\title{
국제개발협력과 아동의 인권
}

이 양 희 성균관대학교 교수. 유엔 아동권리위원장

\section{목차}

I. 서론

II. MDG와 ODA

III. 객관적 평가를 통해 본 한국의 국제개발협력사업

IV. Right to Development와 RBA

V. 아동권리에 기반한 국제개발협력 CRBA

\section{I. 서 론}

한국은 새천년에 들어서면서 세계화와 세계시민이라는 주제가 '국제협력개발' 이라는 화두로 옮겨 지면서 '인권'과 '개발'이라는 새로운 주제와 만나게 된다. 이는 한국 사회가 나아갈 방향을 제시해 줄 뿐 아니라 앞으로 실천해야 할 과제들을 함께 함축하고 있다.

이미 한국은 전 세계가 놀랄만한 경제 성장을 이루어 개발원조의 수원국에서 공여국으로 자리바꿈을 한지 20년이 넘었다. 최근 들어 국제사회에서 확실히 변한 모습이 입증되고 있다. 그 예로 한국은 34 개 국의 $\mathrm{OECD}($ Organization for Economic Cooperation and Development) 회원국 중 '선진국'들만 이 가입할 수 있는 개발원조위원회(Development Assistance Committee: DAC)에 2009년 11월 25 일 정식회원국으로 가입하였다. 2010년에는 G20 Global Summit을 개최하였고, 2011년 제4차 원조효 과를 위한 고위급 포럼(High-Level Forum on Aid Effectiveness)을 부산에서 개최할 예정이다.

한국의 해외원조 사업은 시작은 미미 하였지만, 최근 몇 년 간 양적으로 괄목할 만한 해외원조의 성장을 이루었다. 2006년에는 ODA/GNI 비율이 불과 $0.05 \%$ 였으나 2009년에는 $0.1 \%$ 에 이르렀고, 2015년까지 0.25\%로 확대할 것을 약속한 바 있다. 국제개발협력의 선두주자들에 비하면 한국의 경 험이 일천하지만, 그 동안 우리 정부는 어려운 시행착오 과정을 거치면서 국제개발협력사업의 인프라 를 구축 하는데 성공하였다. 
이러한 과정에서 한국의 국제개발원조를 위한 역할에 많은 관심이 쏠리는 것은 당연한 것이라 할 수 있다. 한국은 이제 국제개발협력사업의 초기단계를 넘어 선진국들과 진정한 파트너로서의 역할을 수행하며 함께 발전해 나아갈 중요한 시점에 놓여있다. 지금 우리가 처한 국제환경은 그 동안 이루어 온 대개도국개발원조사업에 대한 깊은 성찰과 함께 새로운 방향으로의 변화와 발전을 고민하게 한다. 이러한 비전이 현실이 될 수 있는 긍정적인 환경과 외형조건도 구비되었다.

최근 국제사회에서는 인권과 개발의 양립을 위한 '인권에 기반 한 국제개발협력(Rights-Based Approach to International Development Cooperation: RBA'에 대한 논의가 활발히 진행되고 있다. RBA의 핵심은 국제인권규범들에 근거하여 빈곤퇴치를 위한 개발사업을 구축한다는데 있다. 한국 역시 2008년 DAC Special Review of Korea 에서 보다 정교한(sophisticated) 공적개발원조(Official Development Assistant: ODA)를 실시하기 위해서는 향후 인권과 거버넌스(Governance)를 주류화해 나가야 한다고 지적을 받은 바 있다. 이를 실천하기 위해서는 환경에 의해 가장 취약해지기 쉬운 사람들에게 먼저 관심을 집중하고, 동시에 범세계적으로 비준한 협약에 근거하여 개발협력사업을 계획하고 실시한다면 파트너 간 대화의 시작점을 쉽게 마련할 수 있을 것이다.

1948년에 채택된 세계인권선언문(Universal Declaration of Human Rights: UDHR) 이후 여러 국제조약들이 채택되었는데 그 중 가장 많은 국가가 비준한 인권 조약은 아동권리협약(Convention on the Rights of the Child: $\mathrm{CRC}$ )이다. $\mathrm{CRC}$ 는 18세 미만의 모든 이를 아동이라 정의하고 최초로 국제사회가 아동을 권리의 주체자로 인정한 인권협약이다. 본 협약은 1989 년 UN에서 만장일치로 채 택된 이후 현재 193 개국이 비준하였다. ${ }^{1)}$ 다시 말해 한국이 선정한 협력대상국들 모두 $\mathrm{CRC}$ 를 비준한 당사국이며, 그것은 곧 개발협력사업에 아동인권을 주류화 할 의무가 있음을 의미한다.

국제개발협력사업을 추진하는데 있어서 범세계적으로 비준한 국제적 규범인 $\mathrm{CRC}$ 는 빈곤퇴치와 인 류사회가 추구하는 well-being이라는 공통 목표를 달성하기 위한 규준이 될 수 있다. 아동은 진공 속에서 존재하는 것이 아니라 가족, 학교, 지역사회, 더 나아가 한 국가에서 상호의존적인 관계 속에 서 성장한다. 아동은 어느 사회에서도 가장 작은 존재이며 착취와 인권침해에 취약하다. 다수의 연구 를 통해 아동의 인권을 보호하고 그들의 삶의 질을 향상시키는데 초점을 맞추는 것이 장기적으로 빈 곤퇴치에도 효과적이며 지속 가능한 개발의 결과를 가져온다고 밝혀진 바 있다.

이제 우리나라는 더 이상 다른 국가들을 벤치마킹(benchmarking)해서 따라갈 것이 아니라 한 발 앞서서 주도해나갈 필요가 있다. 따라서 필자는 한국이 처해있는 긍정적인 환경을 바탕으로 향후 변 화와 발전을 위하여 앞으로 국제개발협력사업을 추진하는 데 있어 $\mathrm{CRC}$ 에 근거한 '아동 인권에 기반 한 국제개발협력'(Child Rights-Based Approach to International Development Cooperation) 을 한국이 나아갈 방향으로 제안하고자 한다.

1) 미국, 소말리아 제외. 


\section{MDG와 ODA}

2000년 9월에 열린 유엔 밀레니엄 총회에 모인 각국 정상들은 빈곤 감소와 지속 가능한 발전을 공 동의 화두로 인식하고, 이를 해결하기 위해 힘을 모을 것을 다짐하며 '새천년개발선언(Millennium Declaration)'을 채택하였다. 그리고 이를 실천하기 위한 세부계획으로 새천년개발목표(Millennium Development Goals: MDG)를 제시하였다. MDG는 빈곤국의 개발지원을 공동목표화 하려는 흐름을 바탕으로 빈곤해소, 교육, 의료보건, 여성개발, 아동문제 및 환경 등 8개의 기본 목표를 설정하고 2015년까지 이 목표를 달성할 것을 약속하였다.

이후 MDG 목표 달성을 위하여 국제사회는 ODA의 증액을 지속적으로 모색하여 왔으며 2010년 9 월 제 65차 유엔총회에서 MDG 목표달성을 위한 중간점검이 이루어졌다. 본 총회에서 현재까지의 성 과와 달성 가능한 목표들에 대한 논의와 달성하기 어려운 목표들이 부각되었다. 이 중 재원 조달 공 약을 제대로 이행하지 못하는 현 상황에 대해 모든 국가의 노력 증대의 필요성에 대해 공감하고 적극 적으로 노력하고자 하는 정치적 다짐에 대한 고위급간 합의가 도출되었다. 목표를 효과적으로 달성하 기 위해 인권에 대한 고려가 필요함과 몬테레이 합의(Monterrey Consensus)가 재강조 되었다. 반 기문 유엔사무총장은 본 총회 때 여성과 아동 보건 향상을 위한 글로벌 전략(Global Strategy for Women and Children's Health)을 제시하였고, 이를 위한 지원 합의를 도출하는 큰 성과를 거두 었다.

한국은 1996 년 $\mathrm{OECD}$ 가입 후 14 년이 지난 2009년 DAC에 가입하게 되면서 선진대열에 들어섰 다. 1960 년 $\mathrm{DAC}$ 가 설립된 이래 최빈국으로 국제사회의 원조를 받던 국가가 DAC의 정식회원이 되 어 가입한 나라는 한국이 처음이다. 이는 한 국가가 경제적 발전을 이루었기에 이웃나라를 도와주는 차원이 아닌, 국제사회의 선진국들에 버금가는 개발협력사업의 질과 양으로 책임을 다해 기여해야 하 는 도전을 받게 된 것이다.

이제 본격적으로 공여국의 역할을 감당하는 우리나라의 ODA 수준은 아직 미약하다. 한국이 가진 거대한 변화는 국제사회로부터 관심을 얻기 충분했다. 주목의 대상이 된 한국은 DAC 가입 이후 한 해 동안 가입국의 의무인 $\mathrm{ODA}$ 활동에 대하여 현재 여러 각도에서 평가와 재고 중에 있다. 여기에서 국제사회에서의 한국이 걸어가고 있는 수준은 어디에 있는지 살펴보자. 한국의 ODA는 2008년 GNI 대비 $0.09 \%$ 로 27 개국 중 25 위를 차지하였다. ${ }^{2}$ 이후 한국은 2009 년 $0.1 \%$ 로 다소 증액하였으며, 2015 년까지 $0.25 \%$ 로 확대할 계획을 가지고 있다. 그러나 2009년 DAC 가입국의 평균치인 $0.31 \%$ 를 달성하기 위해서는 아직 부족한 수치이다. 2004년에 권고치인 $0.7 \%$ 를 넘긴 스웨덴은 2007년 $\mathrm{OECD} \mathrm{DAC} \mathrm{회원국} \mathrm{중} \mathrm{최초로} \mathrm{GNI}$ 대비 ODA 지출 $1 \%$ 를 달성한 사례를 보여주고 있다. 그 뒤를

2) DAC 회원 22개국 및 Non-DAC 5개국(한국, 슬로바키아, 체코, 폴란드, 헝가리) 총27개국의 ODA 순위 OECD 회원국 중 자료 제출하지 않은 멕시코, 아이슬란드, 터키는 제외 
잇고 있는 룩셈부르크, 노르웨이, 네덜란드, 덴마크에 반하여 한국은 앞으로 부지런히 과제를 수행할 필요가 있다(한국인권재단, 2007).

국제사회는 $\mathrm{ODA}$ 의 양적 확대뿐 아니라 그 효과성 향상에 많은 노력을 기울이고 있다. 이는 $\mathrm{DAC}$ 의 각종 정책권고 및 가이드라인을 준수하는 등 국제 규범과 조화를 이루며 공통의 이해를 성립해야 할 필요성을 불러일으켰고 국제사회는 이에 대한 중요한 논의를 진행하고 있다. 국제사회는 인도주 의, 인권, 빈곤퇴치를 따로 떼어놓고 생각할 수 없다고 이야기한다. 1997년, 당시 코피아난 유엔사무 총장은 유엔시스템 전반에 걸친 인권의 주류화를 요구하였으며, 2003년 2월 로마에서 개최된 '제 1 차 원조조화를 위한 고위급 포럼(High-level Forum on Harmonization)에서 '로마 선언'이 채택된 것을 계기로 유엔기관들은 '권리에 기반 한 접근 $(\mathrm{RBA})^{3)}$ '을 개발 사업에 '어떻게' 적용 할 것인지에 관한 공통이해(UN Common Understanding on the Rights-Based Approach)에 합의를 이루기 도 하였다. 또한 유엔인권최고대표실에서는 빈곤감소전략(Poverty Reduction Strategy)에 사용할 수 있도록 인권 가이드라인을 제시함으로써 $\mathrm{ODA}$ 의 효과적인 전략과 활용방안을 체계적으로 마련해 왔다.

원조효과를 제고하기 위하여 2005년 프랑스 파리에서 열린 '제 2차 원조조화를 위한 고위급 포럼'은 $\mathrm{OECD}$ 회원 및 개발도상국 등 91 개국 대표와 26 개 국제기구 대표가 참석한 가운데 '원조효과 제고에 관한 파리 선언(Paris Declaration on Aid Effectiveness)'을 채택하였다. 이 선언은 주인의식(ownership), 원조일치(alignment), 원조조화(harmonization), 상호책무성(mutual accountability), 성과 중심 관리 (managing for results)를 5가지 원칙으로 제시하면서 2010년까지 달성 할 12 가지 지표를 정해 2006년, 2008년, 2010년에 개발도상국 별 모니터링을 실시하도록 하였다.

2007년 2월 DAC는 ODA에 보다 체계적으로 인권을 통합하기 위한 새로운 실천 정책서(Actionoriented Policy Paper on Human Rights and Development: AOPP)를 채택하였다. 이는 원조의 효과성과 인권의 관계를 강화하기 위한 실천적 원칙을 담고 있으며 개발협력의 새로운 이해와 변화를 시도하는 것이었다. $\mathrm{OECD}$ 는 개발과 인권을 조화시켜 수원국의 인권 향상을 위해 ODA가 사용되어 야 함을 인식하고 이를 위해 '거버넌스 네트워크의 인권실무팀(The GOVNET Human Rights Task Team)'을 두어 인권과 개발의 효과적 연계를 위해 다양한 방안을 논의하도록 했다(OECD, 2007). '권리에 기반 한 접근'이 '개발'에 적용되며 그 효과성을 바탕으로 프로그램 디자인, 적용, 모니터 링, 평가에 이르기까지 점차 체계적인 접근 방법이 함께 제시되면서 그 중요성이 더욱 강조되었다 (UNDP, 2006). 뿐만 아니라 2008년에 개최된 제 3차 아크라 고위급 회담에서는 파리 선언 이행과 원조 효과성 제고 노력의 진전사항 점검 및 가속화를 목적으로 실질적 원조효과 개선 및 원조의 질적 제고 방안을 마련하기 위해 The Accra Agenda for Action(AAA)이 채택되었다.

이후 국제사회는 인권에 기반 한 개발협력을 통해 지역사회의 요구를 충분히 반영하고 그들의 역

3) RBA와 HRBA를 비교하여 설명하는 경우도 있으나 본 원고에서는 RBA로 통일하여 사용한다. 
량을 강화하여 지속성과 책임감의 효과를 증대시킨 사례들을 제시하였다. 이러한 국제적 동향을 따라 한국 역시 국제적 규범과 가이드라인을 따르려는 움직임을 보이고 있다. 효과적인 원조가 이루어지기 위하여 한국의 $\mathrm{ODA}$ 의 질적 제고가 필요하다는 주장 또한 제기되고 있다.

\section{III. 객관적 평가를 통해 본 한국의 국제개발협력사업}

한국의 국제개발협력의 발전방안에 대해 논하는 대부분의 국내 보고서는 한국의 국제개발협력의 차별화 혹은 비교우위를 '한국의 발전 경험과 지혜' 혹은 '인적자원개발'로 설명하고 있다. 이는 우리 의 개발경험과 지혜가 여타 선진국과는 다르며, 이점이 다른 개도국의 발전에 있어 유용하다는 생각 에서 기인한다. 또한 우리의 경쟁력의 근거가 곧 인적자원이므로 이를 전수하는 방법을 통해 선진공 여국과의 차별화 혹은 틈새시장 개척을 모색해야 함을 주장하고 있다. 이러한 주장은 국제개발협력에 있어 ‘한국형 원조모델'이라는 용어로 집약되고 있다.

한국은 그동안 국제개발협력사업을 위한 각종 노력의 성과에 대해 대내적으로 또 자체적으로 높은 점수를 주고 있다. '한국형 원조' 라는 말이 생성되었고, 이에 대한 큰 자부심을 가지고 있음도 부인 할 수 없다. 심지어 ‘한국형 원조 모델’ 을 수출하자는 제안도 있다. 그 동안 국제개발협력을 위한 양 적 성장과 기본적인 인프라 구축을 통하여 기반조성이 이루어 진 것과 국제사회에 자리매김을 하며 우리의 자긍심을 회복한 것은 매우 긍정적인 일이다. 그러나 한국형 모델이라는 용어를 적용하기에는 한국이 경제개발을 이룩한 60,70 년대와 지금의 국제정세는 매우 다르며, 실제로 한국형 모델과 사 업이 무엇인지에 대한 체계적 개념과 컨텐츠 개발이 부족한 실정이다. 또한 한국형이라는 용어는 협 력대상국을 위한 원조보다는 한국의 발전상을 홍보하거나 원조의 가시성에 무게를 두는 공급자 중심 원조로 진행될 수 있으며, 국제사회나 다른 나라와의 협력기회를 감소시킬 수 있다(정우진, 2010).

이제 한국의 국제협력개발사업의 기초기반을 더욱 단단히 다지면서 성숙단계로 가기 위해서 우리 가 해야 할 일은 자랑 보다는 '성찰' 임을 명백히 알아야 할 것이다. 과거 20여 년간 한국의 국제개발 협력사업의 성과는 대부분 소수 민간단체들이 해외원조를 받아 시행한 민주도형 참여식 개발 사업보 다는 관주도로 진행된 새마을 사업의 성과에 집중하고 있는 것이 사실이다. 그러나 냉철한 눈으로 바 라다 볼 때, 1970 년-1980년대에 이루어 진 한국의 개발 사업은 '경제개발사업' 에 치우쳐 있었음을 부인할 사람은 없다고 본다. 이는 많은 부분 사회개발사업을 간과해 왔다는 것을 말하기도 한다.

당시 한국의 개발 사업의 목적을 경제개발에 두었고, 그 목적을 이루기 위해서, 인간의 다양성 인 정 혹은 개별화의 존중 혹은 개인의 선택권은 고려되기 어려웠다. 새마을사업의 성공적 성취를 위한 전략과 접근 방법은 '중앙집권', '관주도', ‘하향식', '성과중심’으로, 일사불란하게 또 신속하게 경제 개발 목표를 달성 하는 것이었다. 이 과정에서 사회개발은 경제적 발전과 소득의 증대가 자연적으로 
이루어진다는 트리클 다운(Trickle Down) 이론이 받쳐 주고 있었다. 그러나 선(先) 경제개발 후(後) 사회개발 전략에 기인 한 생명경시, 인간존중의 결핍, 물질만능주의 가치관이 만들어 내고 있는 한국 사회의 양극화 현상은 한국이 신속히, 그리고 진지하게 풀어야 할 사회적 이슈이다.

전승훈, 이태주, 김달현, 이태희, 전은영(2006)은 한국형 개발협력 모델을 '국제적 원조 규범을 존 중하면서도 선진국들의 전통적인 원조방식과는 차별성을 지니며, 우리나라의 비교우위 분야에 집중 함으로써 원조의 성과를 극대화하고, 우리나라의 국력과 국가 브랜드 가치를 높이고 국제사회에서 아 국의 영향력을 증대시킬 수 있는 한국적인 국제 개발협력 방식'이라고 정의하였다. 정우진(2010)은 한국형 모델을 '국제개발원조의 보편적 가치와 조화되면서도 한국의 경험을 살린 특화된 원조'로 정 의하며, 한국형이라는 용어를 사용하여 한국을 드러내기 보다는 사업의 전반적 특성을 표현하는 명칭 을 사용할 것을 제안하였다. 결국 한국형 모델에서 추구하고자 하는 것은 국제사회의 규범을 따르고 협력하며, 한국의 개발경험의 노하우와 협력대상국의 상황이 조화를 이루어 상생을 이루는 것을 의미 한다. 필자는 한 국가의 모델을 강조하는 것이 수원국의 특수한 상황들을 고려하지 않고 지역 주민들 의 참여적인 개발을 지양하게 될까 우려하는 바이다. 모든 전략과 사업들이 협력과 참여 속에서 도출 되어야 하는데 자칫 잘못하면 과정을 무시한, 결과에 초점을 둔 또 하나의 하향식 개발전략으로 전개 될 가능성이 높기 때문이다.

2010년 제정된 국제개발협력기본법 제 3 조에서는 개발도상국의 빈곤감소, 여성과 아동의 인권향상 및 성 평등 실현, 지속가능한 발전 및 인도주의를 실현하고 협력대상국과의 경제협력관계를 증진하며 국제사회의 평화와 번영을 추구하는 것을 그 기본정신으로 한다. 이러한 기본정신 안에서 정부는 보 다 체계적인 국제개발협력을 위해 2010년 관계부처 합동으로 국제개발협력 선진화 방안을 제시하고, 2011년부터 본격적인 선진화 방안을 추진할 것이다. 국제개발협력 선진화 방안을 구체적으로 살펴보 면, 한국정부는 개도국의 빈곤퇴치와 역량배양(Capacity Building)을 통한 자립능력개발에 중점을 두며, 국제사회의 보편적 가치를 추구하며 인도주의, 인권, 빈곤퇴치 등 지구촌 문제해결에 적극적 참여를 한다. 마지막으로, 국제개발협력을 통해 국민들의 자부심과 세계시민의식을 함양하는 계기로 활용할 계획을 수립하고 있다.

그렇다면, 이를 구체적으로 현실화할 접근방법이 요구된다. 자립능력개발에 중점을 둔 개발과 국제 사회에서 이야기하는 보편적 가치, 원조규범을 준수하면서 국가 브랜드와 국민의 자부심을 향상시키 는 국제개발협력의 접근방법을 고려해 보아야 한다. 


\section{Right to Development와 RBA}

1986년 채택된 발전에 관한 권리선언(Declaration on the Right to Development)은 국제 사회에 개발과 인권에 대한 새로운 의미를 제시하였다. 본 선언문 제 1 조에서 명시되어 있듯이 발전권(Right to Development)은 양도할 수 없는 인권이며 누구나 참여를 통해 경제적 · 사회적 · 문화적 그리고 정치적 발전을 향유할 수 있는 권리와 기본적 자유의 완전한 실현을 의미한다.

발전권의 근원은 세계인권선언(Universal Declaration of Human Rights: UDHR)에서부터 시 작된다. 1948년 채택된 세계인권선언은 제 2차 세계대전이 끝난 후, 온 인류가 당면한 '인권에 대한 필요성'에서부터 시작된다. 세계인권선언문은 구속력이 있는 도구의 필요성을 야기했다. 그러나 인권 에 대한 다양한 국제적 이해 때문에 세계인권선언문에 담겨있는 인권들이 두 가지 조약으로 나뉘었 다. 비로소 경제적 · 사회적 · 문화적 권리에 관한 규약과 시민적 · 정치적 권리에 관한 규약이 탄생한 것이다.

국제사회는 냉전시대를 거치며 인권에 대한 활발한 논의가 진행되는 과정에서 국제개발협력과 인 권을 함께 다루는 새로운 틀(Frame work)의 필요성을 느끼게 된다. 발전에 관한 권리선언은 국제개 발협력에 원조와 인권을 통합하는 새로운 틀을 제시하였으며, 권리를 기반으로 한 개발(RBA)이라는 접근을 도출해 내는데 큰 기여를 하였다. $\mathrm{RBA}$ 는 국제적 인권규준에 기반하여 개발의 전 과정에서 인 권을 증진시키고 보호하는 개념으로, 다음의 원칙에 근거하여 구성되어야 한다:

- 보편성과 불가양성(Universality and Inalienability)

인권은 누구에게나 부여된 보편적이며 양도할 수 없는 권리이다. 어느 누구도 자발적으로 포기할 수 있는 것이 아니고 아무도 이를 앗아갈 수도 없다. 세계인권선언문 제 1 조항에 나와 있듯이, 모 든 인간은 태어날 때부터 자유롭고 존엄하며 평등하다.

- 불가분성(Indivisibility)

인권은 나누어 질 수 없고 시민적, 문화적, 경제적, 정치적, 또는 사회적 권리에 위계가 없고 모두 동등하다.

- 상호의존성 및 상호관련성(Interdependence and Interrelatedness )

모든 권리의 실현은, 전체적 또는 부분적으로 다른 권리의 실현과 연관이 있다는 것을 의미한다.

- 평등 및 비차별성(Equality and Non-discrimination)

모든 인간은 평등하므로 어떤 종류의 차별 없이 권리를 부여 받은 존재이다. 권리를 기반으로 한 
접근은 특히 비차별과 불평등에 초점을 맞추고 있다. 사회적으로 소외된 집단(marginalized group) 의 안녕과 권리를 보호하는 수단에 안전장치(safeguards)가 포함되어야 한다. 권력의 불균형이 강화되거나 새로운 불균형이 생성(창조)되는 것을 지양하기 위하여 지역사회 참여자의 역량을 강 화하여 모든 개발단계에서의 참여해야 한다.

- 참여와 통합(Participation and Inclusion)

모든 인간은 시민적, 경제적, 사회적, 문화적, 그리고 정치적 발전을 위해 능동적이며 자유롭고, 그리고 의미 있는 참여와 기여를 할 권리가 있다.

- 역량강화(Empowerment)

역량강화는 개인의 권리를 요구할 수 있는 능력 향상의 과정이다. 개인의 삶의 변화와 지역사회 발전에 기여할 수 있도록 역량을 키우는데 목표를 두고 있다.

- 책무성과 법치주의 준수(Accountability and respect for the Rule of Law) 권리 소유자(rights holders)와 의무이행자(duty bearers)를 파악하고 의무이행자들이 그들의 의 무를 다할 수 있도록 증진시켜주는 방안이다. 국제적 규준을 국내에 적용하고 책무성의 증진을 위 한 노력이 포함되어야 한다.

RBA를 통한 국제개발협력의 국제적 노력은 1997년 유엔인권최고대표(UN High Commissioner for Human Rights)인 메리 로빈슨에 의해 교육, 식량, 건강 등 다양한 영역에 특별보고관(Special Rapporteur) 및 독립적 전문가(Independent Expert) 제도를 신설하게 하였으며 인권이슈에 대한 아젠 다를 확립하는데도 기여하였다. 그리고 전 유엔사무총장인 코피아난은 유엔 시스템 전반에 인권의 주류 화를 요구, 각 유엔 기관인 UNDP, $\mathrm{WHO}, \mathrm{UNICEF}$ 등 주요 유엔 기관에 인권에 대한 임무(Mandate) 를 포함하는 프로그램을 적용하게 되었다. 메리 로빈슨(2001)은 그간의 연구와 개발경험을 기초로 RBA 의 특징을 다음과 같이 정리하였다. 첫째 책무성(Accountability)의 향상, 둘째 시민역량강화, 셋째 강력한 규범적 명확성과 구체성, 넷째 개발과정에서 보다 수월한 합의 도달과 투명성의 증가, 다섯째 보다 온전하고 합리적인 개발 체계 수립, 여섯째 개발사업에 의한 예상치 못한 피해를 막는 안전장치들, 일곱째 효과적인 분석력, 마지막으로 옹호(Advocacy)활동을 위하여 보다 권위 있는 기반의 필요이다. 


\section{V. 아동권리에 기반한 국제개발협력 CRBA}

지금까지 개발과 관련된 다양한 쟁점을 이야기하였다. 한국의 국제개발협력과 국제사회에서 다루 어지는 여러 논의, 그리고 이 과정에서 양적 확대와 질적 성장의 두 마리 토끼를 잡기 위한 RBA까지 다루어봤다. 그런데 진정한 RBA의 실현을 위해 간과하지 말아야 할 것이 있다. 바로 빈곤 속에 살아 가는 이들 대부분이 아동이라는 것이다. 유니세프(2011)의 보고에 의하면 아시아 지역에만 18 세 미 만 아동 중 3 억 5 천만 이상이 절대적 빈곤에 놓여 있으며, 이들은 사회에서 가장 소외되기 쉽고 빈곤 에 취약하다. 빈곤 속에서 성장한 아동의 취약함은 많은 연구를 통해서도 보고되고 있다. 빈곤은 아 동을 보호하는 환경 구축을 약화시키기 때문에 자연스레 아동 폭력, 학대 및 착취와 깊게 연결되어 있다. 또한 빈곤은 아동이 의료서비스, 충분한 식량, 그리고 기초 교육에의 접근을 제한시키므로 질 병, 영양실조, 그리고 신체적 정신적 발달의 손상과도 연결된다. 더욱이 현재 뿐 아니라 이후 그들에 게 닥친 어려움을 견딜 원동력 및 자신감을 약화시켜 평생 동안 빈곤의 영향력 아래에 놓이며, 세대 간 전이가 일어난다. 그러므로 사회는 아동의 건강, 영양, 그리고 기초적인 교육이 제공될 권리에 대 한 고려와 지속적인 투자를 하지 않고는 빈곤을 경감시켜 나가기 어려운 것이다. 이는 국제개발협력 에 있어 아동인권과 관련한 모든 영역에 참여하여 의사를 표현하고 그것이 존중되고 반영되는 형태로 운영되는 아동인권 주류화 실천의 중요성을 의미한다.

국가, 시민사회, 그리고 가족 내에서 아동 및 여성의 권리 실현을 위해 적극적으로 노력할 때 비로 소 빈곤의 순환이 끊어질 수 있다. 그 중 아동의 건강, 영양, 교육, 그리고 사회적 - 정서적 · 인지적 발달, 그리고 성 평등 달성을 위한 노력은 민주사회 뿐 아니라 평등한 사회를 위한 실천방안이 된다. 또한 아동에 초점을 맞춰 관련 모든 서비스를 제공하고 그들 스스로 선택할 아동의 참여와 자기표현 의 권리를 보장해 줌으로써 미래 세대의 역량강화(Empowerment)에 많은 기여를 하게 된다. 그러므 로 빈곤 감소를 위한 실천은 아동인권이 초점이 되어 아동으로부터 시작되어야 하는 것이다. MDG의 8 개 목표 중 6 개가 아동과 직접적으로 연결되어 있고, 간접적으로는 8 개 모두가 해당된다는 사실이 아동인권을 기반으로 한 국제개발협력에의 중요성을 뒷받침해 준다.

2005년 파리선언에서 새로운 방향의 기준들이 제공되면서 OECD/DAC는 2009년 원조관리지침 (Managing Aid: Practice of DAC Member Countries)에서 원조효과를 지속해 나가기 위해 크로 스커팅 이슈(Cross-cutting issues)의 채택 필요성을 강조하며, 이를 실행하는 방안으로 크로스커팅 이슈의 주류화(mainstreaming) 전략을 제시하였다. 이처럼 아동인권 이슈를 주류화 한다면 파리선 언의 궁극적인 목적인 빈곤과 불평등의 해소, 지속가능한 성장, 그리고 개인의 역량강화 실현에도 기 여할 수 있다.

아동 인권을 주류화하기 위해서는 보다 세심한 접근이 요구된다. 세계인권선언이 존재하지만 $\mathrm{CRC}$ 가 존재하는 이유는 권리주체자인 아동이 가진 고유한 특성 때문이다. 아동권리협약은 경제적, 사회 
적, 문화적 권리와, 정치적, 시민적 권리를 포함하는 가장 포괄적인 인권협약이며, 가장 많은 비준국 을 보유한 협약이다. 또한 최초로 아동을 권리의 주체자로 인정함과 동시에 아동의 특성에 맞는 보호 장치도 강조하고 있다.

전통적으로 아동은 부모나 보호자에게 종속되어 있고 자선 또는 복지의 대상으로 취급되어왔다. 그 러나 1989년 채택된 유엔아동권리협약은 큰 변화를 가져왔다. 국가에 아동 보호 실태를 개선하고 아 동계발을 위한 서비스를 제공하라고 요구하며, 아동에게 영향을 미치는 모든 결정에는 아동의 의견을 반영하게 하는 등 아동을 권리의 주체자로 인정하도록 변화를 가져왔다. 덧붙여 설명하자면 아동권리 협약은 40여개의 조항을 통해 아동이 누리고 보호받을 권리들을 구체적으로 제시한다. 본 협약의 기 본이 되는 4 가지 원칙 다음과 같다:

- 무차별의 원칙: 아동이나 그 부모, 후견인의 인종, 피부색, 성별, 언어, 종교, 정치적 의견, 민족 적·인종적 · 사회적 출신, 재산, 장애여부, 태생, 신분 등에 차별 없이 모든 아동에게 모든 권리가 보장된다.

- 아동의 최상의 이익의 원칙: 당국이 취하는 모든 과정에 아동의 최상의 이익이 최우선으로 고려되 어야 한다. 개발협력에 참여하는 기업 또는 민간단체에도 적용이 된다.

- 의견표명의 권리와 참여의 원칙: 아동의 자유로운 참여와 아동에게 영향을 미치는 모든 절차에서 의견을 표명할 권리가 보장되어야 한다.

- 생명, 생존과 발달의 원칙: 당국은 생명, 생존과 발달을 위해 최대한의 자원을 제공해야 하며 생명 에 관한 권리를 보장해야 한다.

앞서 언급하였듯이 이미 다양한 국제기구와 유엔기관들의 보고서에서 지속가능하고, 책임성 있고, 국제규범을 존중하는 개발을 위해서는 권리에 기반을 둔 개발이 필요하다고 제시하였다. 권리에 기반 을 둔 개발은 가장 취약한 집단이 구조적으로 처하게 되는 다양한 어려움(빈곤 등)의 근본적 원인에 근거하여 스스로 문제를 해결할 수 있는 역량강화(empowerment)를 목적으로 한다. 가장 취약한 집 단이 존중 받는 개발은 다른 모든 집단도 존중 받을 수 있는 가능성을 증대시킨다. 지금 사회에서 가 장 취약한 집단은 '아동’이다. 새천년개발계획(MDG)의 모든 조항이 직 · 간접적으로 아동지원을 명시 하고 있는 것 역시 이러한 사실을 뒷받침한다. 더욱이 아동의 취약성은 성인의 것과는 다른 특성을 지닌다. 가장 취약하고, 성인과는 다른 특성을 지닌 아동의 인권을 고려한 개발이 이루어진다면 공여 국과 수혜국 모두가 상생할 수 있는 개발이 될 수 있을 것이다. 우리나라의 개발원조가 개발도상국의 빈곤퇴치에 효과적으로 기여하고 지속 가능한 발전에 이바지하며, 국제사회의 흐름인 권리에 기반을 둔 국제개발협력 이행을 위해서는 개발원조에서 아동인권 주류화 전략의 필요성을 인식하고 이를 위 한 제도적 기반 마련이 시급히 요구된다. 또한 이를 위하여 아동권리협약을 근거로 한 국제개발 지침 
및 지표 등이 마련되고 이에 근거한 개발이 이루어진다면 개발과정과 결과, 즉 개발의 양적인 면과 질적인 면을 모두 고려한 개발이 이루어질 수 있을 것이다.

이제 한국도 한국적 원조라는 우리만의 명성에서 벗어나 국제적 규범을 따라야 한다. 진정한 인적 자원개발과 다른 공여국과의 차별화, 비교우위는 단순한 수치의 비교에서 오는 것이 아닌 국제적 규 범과 동향을 주도하는 역량으로 좌우될 수 있다. 앞서 언급하였듯이 $\mathrm{CRC}$ 는 가장 보편적이며, 가장 많은 국가가 비준한 국제인권협약이다. 따라서 향후 한국은 $\mathrm{CRC}$ 를 규범으로 하는 아동 인권에 근거 를 둔 개발(CRBA)을 통해 국제협력개발사업을 모색함을 천명하여 국제사회에서 한국의 영향력과 국 제개발의 선진화를 도모할 것을 제안한다.

필자는 앞으로 아동인권에 근거를 둔 국제개발협력사업을 이행하기 위해 필요한 원칙을 몇 가지 제안하려 한다. 첫째로 $\mathrm{CRC}$ 의 기본 원칙을 준수해야 한다. 협약의 기본원칙은 $\mathrm{CRC}$ 의 모든 조항의 근간을 이루는 것으로 $\mathrm{CRBA}$ 를 적용함에 있어 국제적 규범을 형성하는 기본 골격을 이루게 된다. 둘 째, 가장 작은 자(소외된 아동)를 우선해야 한다. $\mathrm{CRBA}$ 를 적용하는 과정에서 아동 중에서도 더욱 소 외되고 취약한 아동을 우선시 하여야 한다. 셋째, 아동을 권리의 주체자로 인정해야 한다. 대부분의 사회에서 아동은 부모나 보호자에게 종속되어 있으며, ‘보이지 않는 존재’로 취급되어 왔다. CRBA를 적용하기 위해서는 아동이 권리의 주체자임을 알리는 과정이 반드시 요구된다. 넷째, 의무이행자 (duty-bearer)들의 책임과 책무성을 강조하여야 한다. 의무이행자는 협약을 비준한 당사국의 정부 만을 이야기하는 것이 아니다. 부모, 교사, 가정, 학교, 지역사회 등 아동의 환경을 구성하는 모든 대 상이 의무이행자이다. 이들은 아동인권을 적용하는 과정에 기꺼이 참여할 수 있어야 한다. 마지막으 로 사회에 존재하는 성(性)을 근거로 한 권력구조를 분석하여 성으로 인한 어떠한 불이익이나 차별이 발생하지 않도록 주의를 기울여야 한다.

$\mathrm{CRBA}$ 는 국제개발협력에 있어 새로운 사고의 전환임은 분명하다. 이제는 아동권리를 실현할 수 있 느냐의 단계를 넘어 '어떻게’ 실현하느냐에 더 많은 노력이 요구된다. 


\section{참고문헌}

\section{1. 국내문헌}

관계부처 합동(2010). 국제개발협력 선진화 방안.

권율 · 김한성 · 박복영 · 황주성 · 홍수연(2006). 우리나라 대외원조정책의 선진화방안 : 국제

개발협력 패러다임의 변화와 한국 $\mathrm{ODA}$ 의 개혁과제. 서울: 대외경제정책연구원

전승훈 · 이태주 · 김달현 · 이태희 · 전응영(2006). 우리나라 무상원조사업의 중장기 정책 및

전략. 서울: 한국국제협력단.

정우진(2010). 한국형 개발협력 모델: 한국적 경험과 비교우위에 근거한 섹터별 프로그램.

서울: 한국국제협력단.

한국인권재단(2007). ODA 정책이 수원국의 인권에 미치는 영향.

\section{2. 국외문헌}

Orford Anne. (2001). Globalization and the Right to Development in: Philip Alston (ed.), People's Rights, pp. 127-145. Oxford Univ. Press.

Arjun Sengupta. (1999). The Right to Development as a Human Right.

Mary Robinson. (2001). Bridging the Gap between Human Rights and

Development: From Normative Principles to Operational Relevance.

Keynote presentation. World Bank. Washington D.C., United states.

OECD. (2007). DAC Action-oriented Policy Paper on Human Rights and Development:

OECD/DAC. (2009). Managing Aid: Practice of DAC Member Countries.

OECD/DAC. (2008). Development Co-operation of the Republic of Korea: DAC Special Review.

UNDP. (2006). Applying a human rights-based approach to development cooperation and programming:

A UNDP capacity development resource. New York: United Nations Development programme.

UNICEF. (2011). The State of the World's Children 2011: Adolescence - An Age of Opportunity.

UNICEF \& UNESCO. (2007). A Human Rights-Based Approach to Education for all.

The Human Rights Based Approach to Development Cooperation-Towords a Common Understanding Among UN Agencies. http://www.hreoc.gov.au/social_justice/conference/engaging_communities/un_common_understanding_rba.pdf

United Nations Secretary-General. (2010). Global Strategy for Women's and Children's Health. The Partnership for Maternal, Newborn and Child Health. http://www.un.org/sg/hf/Global_StategyEN.pdf 